\title{
The challenges of managing diabetes while homeless: a qualitative study using photovoice methodology
}

\author{
Rachel B. Campbell MPP, Matthew Larsen BEd, Anna DiGiandomenico BA, Marleane A. Davidson, \\ Gillian L. Booth MD MSc, Stephen W. Hwang MD MPH, Kerry A. McBrien MD MPH, David J.T. Campbell MD PhD
}

Cite as: CMAJ 2020 July 12;193:E1034-41. doi: 10.1503/cmaj.202537

See related article at www.cmaj.ca/lookup/doi/10.1503/cmaj.210963

\begin{abstract}
BACKGROUND: Minimal consideration has been given to understanding the challenges of managing diabetes while homeless from the perspective of those with lived or living experience. We used a community-based participatory approach to explore these challenges.
\end{abstract}

METHODS: We recruited coresearchers with experiential knowledge of both homelessness and diabetes. Lead researchers conducted research training and facilitated research development by coresearchers. Coresearchers collectively chose to use photovoice methodology to illustrate the challenges of accessing healthy food while homeless and to explore how homelessness more broadly affects diabetes management.
After training in photography technique and ethics, coresearchers took photos to address these objectives and created accompanying narratives using photo elicitation techniques. Lead researchers analyzed photos and narratives, and extracted themes, refined through group discussion.

RESULTS: The 8 coresearchers had type 2 diabetes (diagnosed 18 months to 23 years previously) and had experienced homelessness for periods ranging from 8 months to 12 years. We identified 4 themes from the 17 photos and narratives they produced. Homelessness imposed major demands on emotional and mental health, impairing the ability of those affected to focus on diabetes self-management. Foods provided in shelters were often nutritionally poor or unpalatable. Obtaining housing facilitated diabetes management through stability and autonomy, but cost and lack of knowledge posed challenges to healthy food preparation. Homelessness also presented challenges to accessing diabetes care professionals and prescription medications.

INTERPRETATION: The images and narratives provide a powerful firsthand, indepth account of the challenges faced by people trying to manage diabetes while homeless. Understanding these challenges is the first step in enabling providers and policy-makers to meet the needs of this population.
$\mathrm{P}$ atients with diabetes who experience homelessness often have a difficult time with self-management tasks, given the various health and social challenges they face. ${ }^{1}$ These include financial barriers to accessing medications and testing supplies, food insecurity and difficulty accessing nutritious foods, social barriers and prejudice when seeking medical care, ${ }^{2}$ threats to their emotional well-being from the stressors of being without permanent housing, and challenges storing medication and diabetes supplies. The result of these barriers is, in many cases, suboptimal glycemia. ${ }^{1}$ Hospitalization and diabetesrelated complications have been shown to be substantially higher among people experiencing homelessness. ${ }^{3-5}$
Previous studies have evaluated the impact of homelessness on diabetes. ${ }^{1,6-8}$ However, minimal consideration has been given to the perspective of those with lived experience. ${ }^{9}$ Research that involves patients and community members has a strong track record of leading to changes in program and service delivery. ${ }^{10}$ Interventions designed for patients with diabetes who are facing social disadvantage often have underwhelming results, and community involvement in intervention design is a key element of studies that have shown positive results. ${ }^{11}$ We sought to use a community-based participatory research approach known as photovoice to better illustrate how homelessness affects diabetes management. 


\section{Methods}

The goal of community-based participatory research is to include community members in study design, identification of the research question, data collection, analysis and interpretation. ${ }^{12,13}$ Community members are highly invested in the work, ${ }^{14}$ and are viewed as coresearchers with whom knowledge is cocreated, rather than simply study participants. Lived experience is valued, and maximal participant involvement is viewed as critical. ${ }^{15}$ In this study, the coresearchers formed the Clients with Diabetes Action Committee, a group that met biweekly to share knowledge, set priorities for the group's activities and undertake research related to those priorities.

\section{Participants}

Group members were recruited between November 2018 and January 2019 via posters on community boards and in shelters, and through existing community groups in Toronto. We recruited people who had lived or living experience of both diabetes and homelessness. We defined homelessness broadly as a lack of stable, safe, permanent or appropriate housing, including being provisionally sheltered, emergency sheltered or unsheltered. We included people with either type 1 or type 2 diabetes mellitus by self-report, but excluded those with diabetes risk factors only. We excluded people who lacked fluency in English and those with active, severe mental illness. Further details regarding the creation of the group are described elsewhere. ${ }^{16}$

The group met regularly in a community space for 2 hours every other week. Group members received a meal, an honorarium and transit tokens at the conclusion of each meeting. The group was highly engaged and had an overall attendance of $82 \%$ over 7 months.

\section{Study design}

The researchers presented a variety of approaches and methods to the community coresearchers, including both quantitative and qualitative methods. Group members expressed interest in pursuing photovoice, which is a well-described qualitative methodology by which coresearchers "record and reflect their personal and community strengths and concerns, [and] promote critical dialogue and knowledge about personal and community issues through group discussion of photographs." 17 Since it was originally introduced by Wang in the mid-1990s, ${ }^{18}$ photovoice has been used in the study of a variety of health and social contexts, ${ }^{19}$ generally with the objective of enhancing the voices of those who are oppressed or underserved through the theoretical lens of emancipation or empowerment. ${ }^{20}$ Photovoice makes unique use of images as source material for illustrating and understanding the perspectives of participants. In particular, this approach leverages the ability of images to influence policy, based on theoretical frameworks of problem-posing health education and the role of images and media in culture production. ${ }^{17,18}$ Photovoice situates greater control of the findings in the hands of the coresearchers, and is therefore well suited to community-based participatory research.

\section{Development of the research objectives}

The research questions were developed using concept mapping, which is an in-depth, participatory, multisession, priority-setting exercise. ${ }^{21}$ Full details of this process are described elsewhere. ${ }^{22}$ Briefly, coresearchers were led in brainstorming sessions to answer the question "What are some ways, good or bad, that diabetes might be affected by homelessness?" The coresearchers generated many responses, which they then grouped together. Each statement was rated by group members in regard to its impact on managing diabetes. This process revealed that healthy eating was perceived by the group as the greatest challenge of managing diabetes while homeless. ${ }^{22}$ This led to the following research objective: take a photograph that shows what makes it challenging to eat well with diabetes while experiencing homelessness.

Although diet was the top collective priority of the group, coresearchers expressed other individual priorities. To allow more latitude, a second, more open-ended research objective was: take a photograph that depicts something relating to homelessness that has been a major help or barrier to your diabetes self-management.

\section{Data collection}

The group worked individually and collectively on the project over the course of 4 months, including 12 unique group sessions. Each coresearcher was provided with a point-and-shoot digital camera (Nikon Coolpix A100). Two group sessions were dedicated to learning about photography, taught by a professional photographer. The group spent a portion of 2 additional sessions discussing ethical issues surrounding the use of photography in research, including power dynamics, privacy and intrusion, and representation. ${ }^{23,24}$ We devoted several sessions to developing the skill of telling a story using a photograph.

Some group members produced 1 photo for each research question, and others took dozens. Coresearchers presented their photos to the group for feedback and discussion to help select the one that best related to each research objective. Each individual coresearcher had final decision-making authority over which photo(s) they wanted to use. We asked all coresearchers to consider signing release forms for each of their image and narrative combinations, and to specify the name by which they would like to be recognized (including being given the choice of using initials or a pseudonym or being referred to as anonymous). We report the identities of coresearchers and attribute their content according to their expressed wishes.

\section{Data analysis}

We analyzed selected photos in 4 steps. First, for each selected photo, the facilitators led the group member through a series of 6 exploratory photoelicitation questions using the SHOWeD method: ${ }^{25}$ What do you see here? What is happening here? How does this relate to diabetes in our lives? How does this relate to homelessness in our lives? Why does this exist? What can be done about it?

After considering these questions individually, each coresearcher shared their reflections with the group. They then wrote 
Table 1: Coresearcher characteristics

No (\%) of participants *

\section{Characteristic}

Age, yr

$<45$

45-64

$\geq 65$

Gender

Woman

$5(62)$

Man

Race

White

Non-White

Housing status at beginning of study

Homeless (shelter or rough sleeping)

Transitional or temporary housing

Tenuously or unstably housed

$3(38)$

Duration of homelessness/unstable housing, mean (range)

$2.81 \mathrm{yr}(8 \mathrm{mo}-12 \mathrm{yr})$

Diabetes type

Type 1

Type 2

$8(100)$

Duration of diabetes, mean (range)

$7.21 \mathrm{yr}(18 \mathrm{mo}-23 \mathrm{yr})$

Diabetes treatment

Lifestyle only (no medical therapy)

Noninsulin medications only

$3(38)$

Insulin injections and/or other medications

Diabetes care providers

Medical doctor

Primary care only

Specialist involvement

Allied health providers

Nurse

1 (12)

Dietitian

2 (25)

Pharmacist

1 (12)

Self-reported diabetes complications

Coronary disease or myocardial infarction

Stroke or cerebrovascular accident

Foot ulcers (wounds), gangrene, amputations

1 (12)

Diabetic nephropathy

1 (12)

Diabetic retinopathy

1 (12)

Neuropathy symptoms

5 (62)

Self-reported comorbidities

Hypertension

7 (88)

Hypercholesterolemia

$5(62)$

Obesity

$6(75)$

Sleep apnea

$4(50)$

Depression

$6(75)$

Anxiety problems

$4(50)$

Psychosis

2 (25)

Alcohol addiction

4 (50)

Drug addiction

$5(62)$

*Unless indicated otherwise. 
a narrative to accompany the photo. Lead researchers worked with each coresearcher to develop the narratives that accompanied each photo. Group members also helped each other as peer editors, if requested by the photographer.

The lead researchers (R.B.C., D.J.T.C.) independently identified potential themes that were woven through all photos and narratives, which were then discussed with coresearchers. Coresearchers then provided their impressions of how the photographs were linked together, and the commonalities and differences between the images. The group collectively chose "Home Sweet Home(less)" as the title for the project.

Finally, the discussion from this meeting was combined with further analysis by lead researchers (R.B.C., D.J.T.C.), who coded all narratives in word processing software using inductive thematic analysis. ${ }^{26}$ Analysis was informed by a framework for understanding the role of socioeconomic position in diabetes outcomes, ${ }^{27}$ with the objective of clarifying and summarizing the themes of the coresearchers' work.

\section{Knowledge translation}

Once finalized, we displayed the selected photos with accompanying narratives in a public exhibit at our research institute. The photos and narratives were supplemented by biographies and portraits of each photographer. Group members were present to discuss their photos and answer questions from attendees. After its initial showing in Toronto, the exhibit was subsequently displayed at various scientific conferences and in public spaces for a total of 18 days in 8 locations in Canada. We tried to have group members present at each installation of the exhibit.

\section{Ethics approval}

This study was approved by the research ethics boards of the University of Calgary and St. Michael's Hospital/Unity Health Toronto.

\section{Results}

Despite our targeting a group size of approximately 12 coresearchers, the final group consisted of 8 individuals who met the inclusion criteria and continued to participate regularly. All group members had received a diagnosis of type 2 diabetes 18 months to 23 years previously and had experienced homelessness or unstable housing for 18 months to 12 years (Table 1 ). The group included 3 men and 5 women, representing a diversity of ethnic origins and ages. At the beginning of group meetings, 2 had become stably housed, 3 were staying in transitional housing, and 3 were living in shelters or sleeping outdoors. The photovoice process yielded 17 photos with accompanying narratives and 4 major themes. Photos are presented in the supplementary Appendix 1, available at www.cmaj.ca/lookup/doi/10.1503/ cmaj.202537/tab-related-content. The 4 themes were as follows: the effects of homelessness on emotional and mental health, and on diabetes self-management; barriers to healthy eating in shelters; benefits and challenges to diabetes management after getting housed; and access to diabetes care professionals and prescription medications.

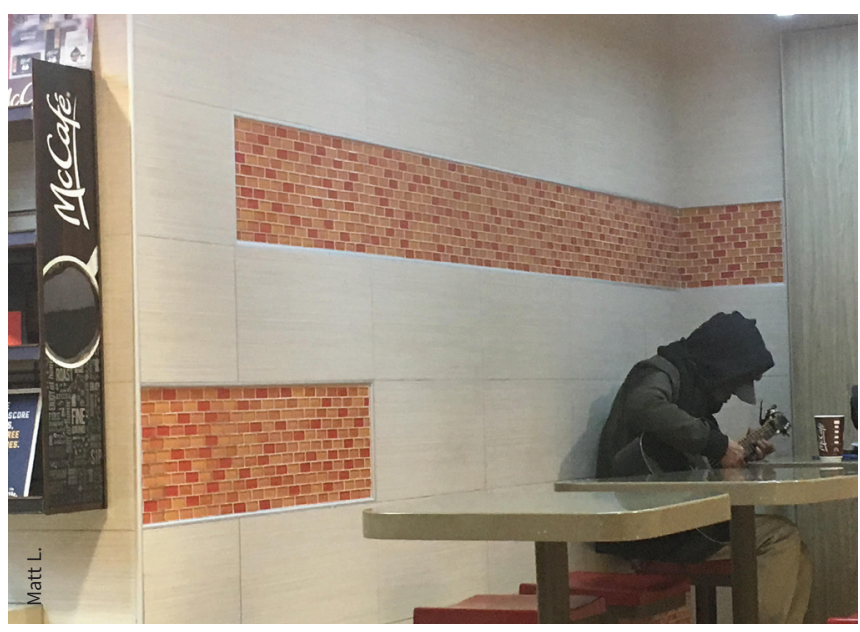

Figure 1: Always Darkest. "A solitary figure sits in the corner of a local McDonalds, strumming their guitar inaudibly so as to not draw the ire of restaurant staff and be kicked out into the frigid mid-March pre-dawn. I see myself in this picture, except instead of a guitar I'm hunched over a cell phone, utilizing the restaurant's wifi. A large chocolate milkshake and two McDoubles provide the highlight of my day while also allowing me to kill myself slowly due to my type 2 diabetes. McDonald's is everywhere, open $24 / 7$, cheap, and (perhaps most importantly) familiar. Everything always tastes the same as I remember it. This dependability literally sugared the pill of chaos I was forced to swallow everyday while homeless. The fear of future diabetic complications didn't even register when each moment was a nightmare" (Matt L.).

\section{The effects of homelessness on emotional and mental health, and on diabetes self-management}

Coresearchers described homelessness as a highly stressful state that demands that those in its grasp prioritize their most basic needs (Figure 1). The mental energy and time required to figure out where one can safely spend the night, quell one's hunger and make it through another day leave little room for high-order tasks, like managing diet, medications and exercise. Regarding the anonymous individual that was the subject of his photo, one coresearcher wrote, "I doubt if he knew or cared whether or not he had diabetes. The thought of him diligently taking medication and blood glucose readings is almost laughable" (Matt 3). In addition, homelessness can be an oppressively depressing state for many. "When I was sitting on a road drinking alcohol, I didn't give a care in the world about my diabetes because I didn't have a home at the time. I was mad..." (Georgina 2). Familiar foods were described as the only source of joy in an otherwise depressing day, even if they were not healthy choices for people managing diabetes: "A large chocolate milkshake and two McDoubles provide the highlight of my day..." (Matt 1). Group members' narratives also described feelings of fear, uncertainty and injustice ("why is this happening to me?") about the daily challenges they face in trying to meet their most basic needs.

\section{Barriers to healthy eating in shelters}

Photos showed that eating healthily while residing in shelter presents major challenges (Figure 2). The meals and snacks they provide are often poor in nutritional value. Clients are also unaware of the nutritional information (i.e., carbohydrate content), which is not made readily available. "It seems healthy," 

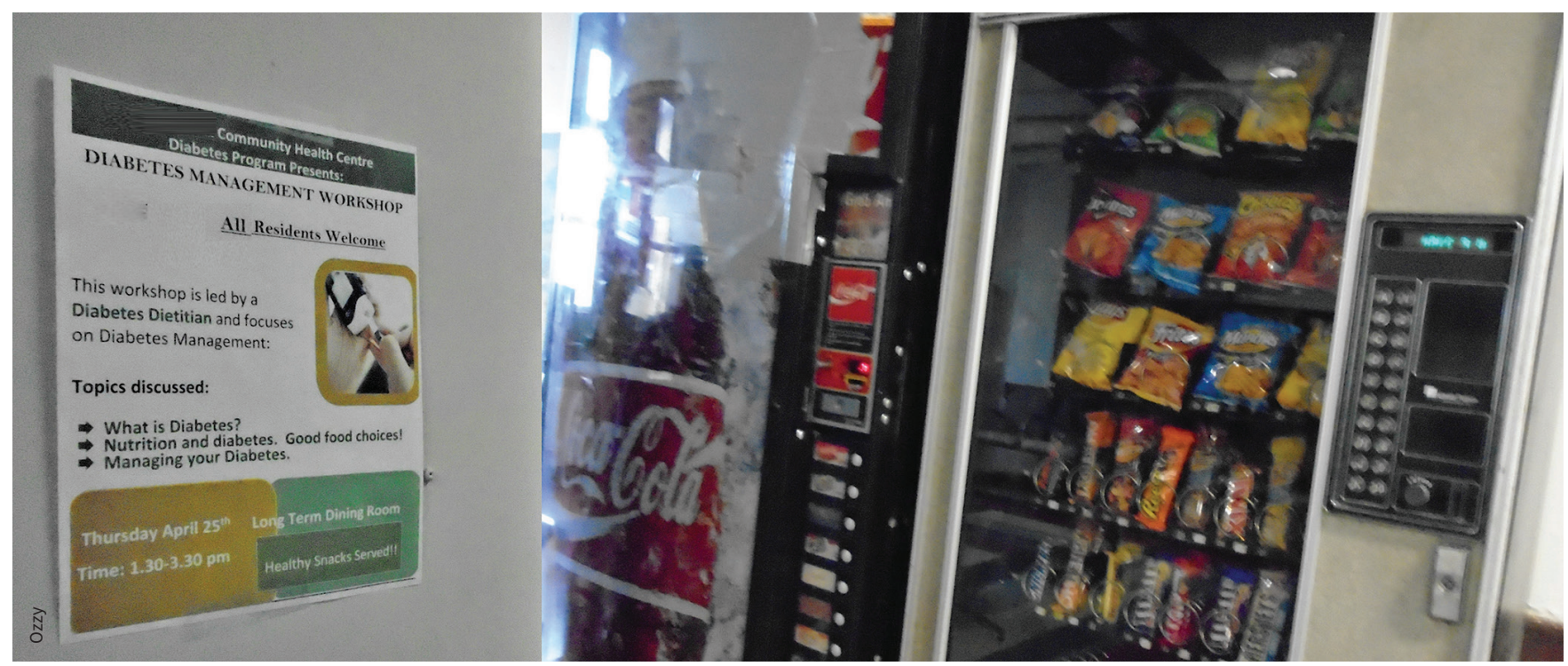

Figure 2: Contradiction. "I moved into a homeless shelter in Toronto one year ago. The shelter recently posted the flyer you see in the picture - which means that the shelter is aware of the problem of diabetes. However, in the background you'll see two vending machines. The left one selling highsugar pop cans, and the right one selling sweet junk chocolates and sweets. Both of these vending machines do brisk business - as they need to be refilled every Sunday. Since everyone in the shelter is at risk of diabetes, take the machines out and if people want to get sweets, they have to go out to find them. Or surprise us one week and fill it with water or apples or sandwiches" (Ozzy).

wrote one group member, regarding food she was provided. She had to do "[her] own independent reading and research to arrive at knowledge about healthy food choices to manage diabetes. These are not lessons given in homeless shelters" (Jasmine 1). She also spoke of having to substitute unhealthy foods provided at the shelter with healthier foods she bought herself.

Meals are also often unpalatable, according to group members. One coresearcher wrote about having to "force [himself] to swallow the mush" that he was given in shelter (Matt 2), contributing to the already bleak state of homelessness, as well as the desire to seek out something more appetizing. Often the only on-site alternatives to the meals provided by the shelter are candy and soft drinks from vending machines, which were noted by one participant to do "brisk business" (Ozzy 1), despite ironically being situated directly adjacent to an advertisement for diabetes education sessions. Most shelters and many transitional housing programs do not have kitchens available for client use, so preparing one's own meals is not an option. This lack of autonomy makes it nearly impossible to follow healthy eating guidelines.

\section{Benefits and challenges to diabetes management after getting housed}

Permanent housing provides much-needed stability and autonomy to manage this complex disease (Figure 3). One coresearcher wrote about how her life had changed since she got a place of her own: "Now I have a home where I can keep my medications and I know where they are. I don't have to keep them in a backpack or garbage bag that I carried around with me. I keep my blisterpacked medications on the table, where I can remember to take them. And I don't have to worry about people stealing my medications anymore. My diabetes is bad, but it would have been a lot worse if I didn't get a home" (Georgina 2).

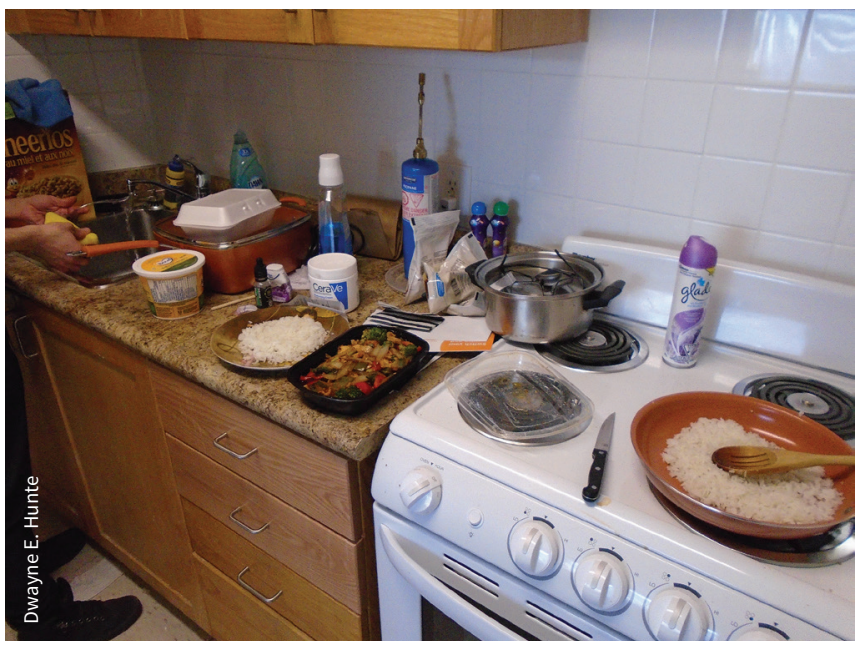

Figure 3: The Diabetic Wish ... "When you look at this you see a kitchen, to a diabetic, you see a life saver. Being in a shelter, yes... you do have the choice of eating a doughnut or a banana, however let's get real... do you care what you are fed in a shelter?! The important thing is whether I'm being fed or if I'm going to bed hungry. Being able to cook your own meals may not be important to many, but to me it's a privilege. Not having to worry if the food is high in sugars or carbs, but the choice of eating a measured portion of rice instead of pasta, and all the vegetables in the world. Being able to prepare my meals is such a blessing, one that I won't take for granted, because I know how quickly I can lose everything AGAIN!!!" (Dwayne E. Hunte).

However, independent housing also comes with a new set of challenges. Healthy food can be expensive for those on a limited income. People who are newly housed often rely on food banks to supplement their groceries, but what is provided is usually high in simple carbohydrates and low in protein and fibre, as shown by a group member's photo of the food they had received from a food bank (Appendix 1). 


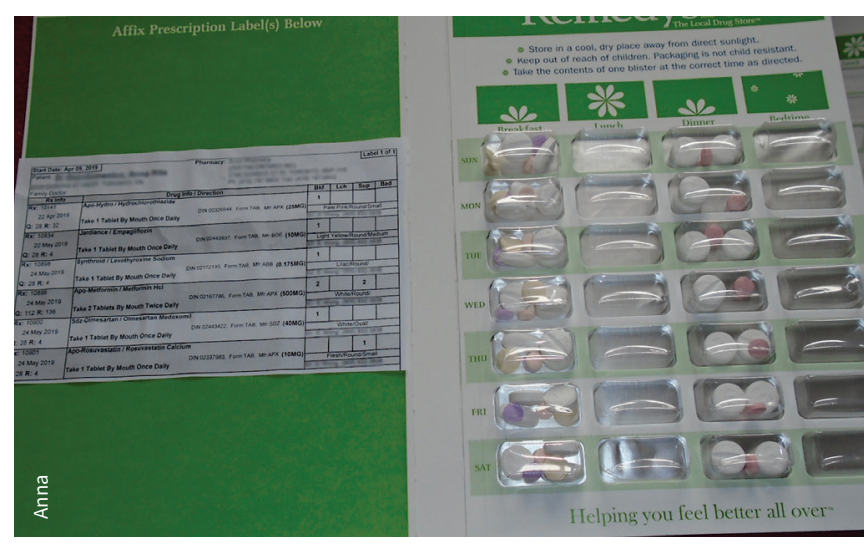

Figure 4: Patient Pays ... \$97.14. "Are you kidding me?! That is for one week of meds. I guess this week this girl will need to make-do with the food that is in her cupboard ... So beans it is again. Tell me, where is the justification? Why must homeless individuals with diabetes have to decide if this week they eat properly or if the get their meds to control their diabetes? Then of course there is the fear of your meds being stolen from you. So now not only are you without food but without meds too. What's it going to take for someone to take action against the injustice? As a homeless diabetic, I have to decide if I eat this week, or if I refill my prescriptions. I know this fight is going to be hard, but this is one woman who is not giving up ... So bring on the challenge, I'm ready for the fight" (Anna).

For some, lack of knowledge of how to prepare nutritious meals caused them to resort to consuming readily accessible, unhealthy, processed foods. Several group members spoke of learning about nutrition, diet and preparing healthier foods. One coresearcher shared that she attends "diabetes groups to learn how to cook healthier food and manage diabetes by managing diet" (Cat 1). Another stated that "being able to cook your own meals may not be important to many, but to me it's a privilege" (Dwayne 2).

\section{Access to diabetes care professionals and prescription medications}

Homelessness does not only affect the dietary aspects of diabetes management. It also presents challenges to accessing health services and adhering to prescription medication regimens (Figure 4). Coresearchers reported the difficulties of keeping up with appointments when one is experiencing homelessness. Coresearchers stated that making these services easier to access, either by providing multiple services in 1 location or bringing providers to the places where people live increased their ability to attend appointments.

Several coresearchers commented on the cost of prescription medications, as they either did not have or did not qualify for public pharmaceutical coverage. Those who had coverage also commented on restrictions, such as the payer not covering the replacement of medications if they were stolen. Concerning the cost of her prescription medications, one coresearcher wrote, "As a homeless diabetic, I have to decide if I eat this week, or if I refill my prescriptions" (Anna 2). Other challenges with medications include lack of adequate storage (given the lack of a private and secure place) and difficulties with adherence because of irregular schedules and lack of routine.

\section{Interpretation}

We engaged community coresearchers to illustrate the many challenges of managing diabetes faced by people experiencing homelessness. Our process began with a very open-ended question to explore diabetes and homelessness through a communitybased participatory research approach. Although individuals' experiences were diverse and nuanced, there was consistency in the barriers they faced. Our coresearchers identified that food and diet-related considerations were their greatest concern, but our photovoice project illustrated that, beyond glycemic ramifications, food also affected mental and emotional well-being, and that these challenges often persisted even once an individual was stably housed. Many other diabetes-related challenges exist that were not pursued by our coresearchers as they were deemed to be of lesser importance in their minds.

One unique aspect of community-based participatory research is that projects are generally undertaken with an explicit objective to contribute to meaningful change in policy or practice. Clear practice implications can be drawn from the results of this project; people experiencing homelessness who have diabetes need more support for improved nutrition and self-management, both while homeless and newly housed. Our findings have ramifications for shelters, meal providers, health care delivery organizations and particularly for funders. Our knowledge translation efforts have included presentations at local organizations and photo exhibits at national and international academic conferences. Other knowledge translation has occurred through advocacy efforts by coresearchers. Several group members have taken the initiative to talk to staff at their shelters or other places where they get meals about offering more diabetes-friendly meal options. At least 2 programs or shelters have committed to changing the meals they provide. One group member is in ongoing talks regarding these issues with the federal politician representing her constituency.

Although the challenges of co-occurring homelessness and diabetes $^{1,2}$ and their potential solutions (e.g., housing, ${ }^{28,29}$ improved health care access ${ }^{30}$ ) have been previously discussed, the photos and narratives, created by coresearchers with experiential knowledge, provide new richness and power to the discussion. Very few studies in diabetes have been conducted in a participatory fashion, fully including the voice and perspective of those with lived experience. ${ }^{9}$ Other photovoice projects have been conducted with people experiencing homelessness, ${ }^{31}$ including 2 that reported access to food was a challenge, ${ }^{32,33}$ but our study specifically focused on challenges related to diabetes management in the context of homelessness.

We recruited a diverse group of community coresearchers for this project that represented a broad range of perspectives and experiences. Because the research topic and questions were developed in partnership with the group members, they were highly invested in the work. Additionally, because the photovoice project was conducted within a community-based participatory research project, ${ }^{16}$ the group spent substantially more time working together than in many other stand-alone photovoice projects. The relationships between investigators and 
group members were well established before the commencement of the photovoice project, and this foundation of trust helped to facilitate the elicitation process. We devoted many hours over multiple group meetings to this work, adding to the rigour of our photovoice project. The strength of this study is its ability to tell a convincing and powerful narrative that we hope will continue to inform researchers, clinicians and policy-makers, and inspire them to advocate for this population and to improve their ability to access healthy foods and other necessary goods and services.

\section{Limitations}

A limitation of this study was the small number of coresearchers, dictated by the size of the group in the parent community-based participatory research study. It was therefore a self-selected group of community members who expressed interest in this work. However, the intimate size of the group allowed for more openness and a richer, more honest discussion, as we were able to build and develop trust between coresearchers and the lead researchers. It also permitted lead researchers more time to engage with each coresearcher for elicitation and editing of narratives. The community-based participatory research process required group members to commit to attending regular meetings over a period of 6-8 months. This requirement precluded participation from people who were in acute crisis (e.g., from housing instability, violence, mental illness, health conditions or addiction). Another limitation was the lack of participation from adolescents, young adults or people with type 1 diabetes; nevertheless, the group was diverse in age, gender, ethnicity, experience with homelessness and diabetes treatment. As with many qualitative studies, the number of participants and the nature of the work dictate that one should use caution in generalizing to other populations and locations, given the context-specific nature of the findings. Because the group chose the research priorities and question, the research question risks not being of top relevance to populations in other jurisdictions. Finally, the academic researchers took a lead role in the analysis of the data generated by the coresearchers, and we acknowledge that our perspectives are influenced by our experiences and positions of privilege. We have considerable experience working with those who have lived experience of homelessness but lack that experience ourselves. We have tried to highlight the voice of coresearchers rather than imposing our own lens upon their work, wherever possible.

\section{Conclusion}

The incidence of homelessness ${ }^{34}$ and type 2 diabetes among those who face social vulnerabilities ${ }^{35-37}$ has consistently increased, so we expect the issues identified by coresearchers in this study to persist. This study provides a starting place for policy-makers to think about addressing areas of concern for people with lived experience of both diabetes and homelessness. Finally, we hope that this project will show other health researchers that community-based research, including photovoice, with this population is feasible, valuable and essential for understanding this population's needs and views.

\section{References}

1. Hwang SW, Bugeja AL. Barriers to appropriate diabetes management among homeless people in Toronto. CMAJ 2000;163:161-5.

2. Campbell DJ, O'Neill BG, Gibson K, et al. Primary healthcare needs and barriers to care among Calgary's homeless populations. BMC Fam Pract 2015;16:139.

3. Benoit SR, Zhang Y, Geiss LS, et al. Trends in diabetic ketoacidosis hospitalizations and in-hospital mortality - United States, 2000-2014. MMWR Morb Mortal Wkly Rep 2018;67:362-5.

4. Booth GL, Hux JE. Relationship between avoidable hospitalizations for diabetes mellitus and income level. Arch Intern Med 2003;163:101-6.

5. Schlienger J. Some recent figures about diabetes in France [article in French]. Met Dis Med 2009;3:98-9.

6. Axon RN, Gebregziabher M, Dismuke CE, et al. Differential impact of homelessness on glycemic control in veterans with type 2 diabetes mellitus. J Gen Intern Med 2016;31:1331-7.

7. Davachi S, Ferrari I. Homelessness and diabetes: reducing disparities in diabetes care through innovations and partnerships. Can J Diabetes 2012;36:75-82.

8. Elder NC, Tubb MR. Diabetes in homeless persons: barriers and enablers to health as perceived by patients, medical, and social service providers. Soc Work Public Health 2014;29:220-31.

9. Harris J, Haltbakk J, Dunning T, et al. How patient and community involvement in diabetes research influences health outcomes: a realist review. Health Expect 2019;22:907-20.

10. Crawford MJ, Rutter D, Manley C, et al. Systematic review of involving patients in the planning and development of health care. BMJ 2002;325:1263.

11. Glazier RH, Bajcar J, Kennie NR, et al. A systematic review of interventions to improve diabetes care in socially disadvantaged populations. Diabetes Care 2006;29:1675-88.

12. Israel BA, Schulz AJ, Parker EA, et al. Critical issues in developing and following community-based participatory research principles In: Minkler M, Wallterstein $\mathrm{N}$, editors. Community-based participatory research for health. San Francisco: Jossey-Bass; 2003:56-73.

13. Israel BA, Schulz AJ, Parker EA, et al. Community-based participatory research: policy recommendations for promoting a partnership approach in health research. Educ Health (Abingdon) 2001;14:182-97.

14. Viswanathan M, Ammerman A, Eng E. Community-based participatory research: assessing the evidence. Rockville: Agency for Healthcare Research and Quality; 2004.

15. Israel BA, Schulz AJ, Parker EA, et al. Review of community-based research: assessing partnership approaches to improve public health. Annu Rev Public Health 1998;19:173-202.

16. Campbell DJT, Campbell RB, DiGiandomenico A, et al. Using community-based participatory research approaches to meaningfully engage those with lived experience of diabetes and homelessness. BMJ Open Diabetes Res Care 2021;9:e002154. doi:10.1136/bmjdrc-2021-002154.

17. Wang C. Photovoice: a participatory action research strategy applied to women's health. J Womens Health 1999;8:185-92.

18. Wang C, Burris MA. Photovoice: concept, methodology, and use for participatory needs assessment. Health Educ Behav 1997;24:369-87.

19. Catalani C, Minkler M. Photovoice: a review of the literature in health and public health. Health Educ Behav 2010;37:424-51.

20. Wang C, Burris MA. Empowerment through photo novella: portraits of participation. Health Educ Q 1994;21:171-86.

21. Trochim WMK. An introduction to concept mapping for planning and evaluation. Eval Program Plan 1989;12:1-16.

22. Grewal EK, Campbell RB, Booth GL, et al. Using concept mapping to prioritize barriers to diabetes care and self-management for those who experience homelessness. Int J Equity Health 2021;20. doi:10.1186/s12939-021-01494-3.

23. Creighton G, Oliffe JL, Ferlatte 0 , et al. Photovoice ethics: critical reflections from men's mental health research. Qual Health Res 2018;28:446-55.

24. Wang CC, Redwood-Jones YA. Photovoice ethics: perspectives from Flint Photovoice. Health Educ Behav 2001;28:560-72.

25. Wang C, Burris MA. Photovoice: concept, methodology, and use for participatory needs assessment. Health Educ Behav 1997;24:369-87.

26. Braun V, Clarke V. Thematic analysis. In: Cooper H, editor. APA handbook of research methods in psychology. Vol 2. Washington (D.C.): American Psychological Association; 2012. 
27. Brown AF, Ettner SL, Piette J, et al. Socioeconomic position and health among persons with diabetes mellitus: a conceptual framework and review of the literature. Epidemiol Rev 2004;26:63-77.

28. Keene D, Henry M, Gormley C, et al. 'Then I found housing and everything changed': transitions to rent-assisted housing and diabetes self-management. Cityscape 2018;20:107-18.

29. Keene DE, Guo M, Murillo S. "That wasn't really a place to worry about diabetes": Housing access and diabetes self-management among low-income adults. Soc Sci Med 2018;197:71-7.

30. Campbell D, Campbell R, Booth G, et al. Innovations in providing diabetes care for individuals experiencing homelessness: an environmental scan. Can J Diabetes 2020; 44:643-50.

31. Seitz C, Strack R. Conducting public health photovoice projects with those who are homeless: a review of the literature. J Soc Distress Homeless 2016;25:33-40.
32. Bredesen J, Stevens M. Using photovoice methodology to give voice to the health care needs of homeless families. Am Int J Contemp Res 2013;3:1-12.

33. Valera P, Gallin J, Schuk D, et al. "Trying to eat healthy": a photovoice study about women's access to healthy food in New York City. Affilia 2009;24: 300-14.

34. Everyone counts: highlights. Preliminary results from the second nationally coordinated point-in-time count of homelessness in Canadian communities. Ottawa: Employment and Social Development Canada; 2018.

35. An economic tsunami: the cost of diabetes in Canada. Toronto: Canadian Diabetes Association; 2009.

36. Diabetes in Canada: highlights from the Canadian Chronic Disease Surveillance System. Ottawa: Public Health Agency of Canada; 2017.

37. Lin J, Thompson TJ, Cheng YJ, et al. Projection of the future diabetes burden in the United States through 2060. Popul Health Metr 2018;16:9.

\section{Competing interests: None declared.}

This article has been peer reviewed.

Affiliations: Department of Medicine (R.B. Campbell, D.J.T. Campbell), University of Calgary Cumming School of Medicine, Calgary, Alta.; Clients with Diabetes Action Committee, MAP Centre for Urban Health Solutions (Larsen, DiGiandomenico, Davidson), Li Ka Shing Knowledge Institute, St. Michael's Hospital, Unity Health Toronto; MAP Centre for Urban Health Solutions (Booth, Hwang), Li Ka Shing Knowledge Institute, St. Michael's Hospital, Unity Health Toronto; Department of Medicine, Faculty of Medicine (Booth, Hwang), University of Toronto, Toronto, Ont.; Department of Community Health Sciences (McBrien, D.J.T. Campbell), Family Medicine (McBrien), and Cardiac Sciences (D.J.T. Campbell), University of Calgary Cumming School of Medicine, Calgary, Alta.

Contributors: David Campbell, Rachel Campbell, Matthew Larsen, Anna DiGiandomenico, Marleane Davidson and the other community coresearchers contributed to the conception and design of the work. Matthew Larsen, Anna DiGiandomenico, Marleane Davidson acquired the data, under the direction of David Campbell and Rachel Campbell, with input from Kerry McBrien, Gillian Booth and Stephen Hwang. Matthew Larsen, Anna DiGiandomenico, Marleane Davidson and other community coresearchers analyzed data with David Campbell and Rachel Campbell. All of the authors and community coresearchers contributed to interpretation of the data. The first draft of the manuscript was written by Rachel Campbell and David Campbell. Matthew Larsen, Anna DiGiandomenico, Marleane Davidson, Kerry McBrien, Gillian Booth and Stephen Hwang contributed substantively to critically revising the manuscript. All of the authors gave final approval of the version to be published and agreed to be accountable for all aspects of the work.
Content licence: This is an Open Access article distributed in accordance with the terms of the Creative Commons Attribution (CC BY-NC-ND 4.0) licence, which permits use, distribution and reproduction in any medium, provided that the original publication is properly cited, the use is noncommercial (i.e., research or educational use), and no modifications or adaptations are made. See: https://creativecommons.org/ licenses/by-nc-nd/4.0/

Funding: Funding to undertake this study was provided by Alberta Innovates through a Clinician Fellowship for Dr. Campbell, and by the Cal Wenzel Family Cardiometabolic Research Fund (Department of Medicine, Cumming School of Medicine) and the Research \& Training Program for Health and Vulnerable Populations (O'Brien Institute for Public Health, Cumming School of Medicine) through grants provided to Dr. D. Campbell. The funders had no role in the design or conduct of the study, nor in the writing or approval for publication of the manuscript.

Data sharing: All data generated by this study (images and narratives) are presented in the supplementary appendix.

Acknowledgements: The authors acknowledge help received from Ms. Linda Monteith who provided photography training. The authors also thank Dr. Pat O'Campo, Dr. Priya Vasa and Dr. Janet Parsons for their consultations in the conduct of this research. The authors acknowledge the staff of the TD Centre for Learning for hosting the community group. More than anything, this project would not have been possible without the dedication, time and talents of the community coresearchers. The authors thank them for sharing of themselves to help everyone to better understand the struggles of this population.

Accepted: Apr. 22, 2021

Correspondence to: David Campbell, dcampbel@ucalgary.ca 